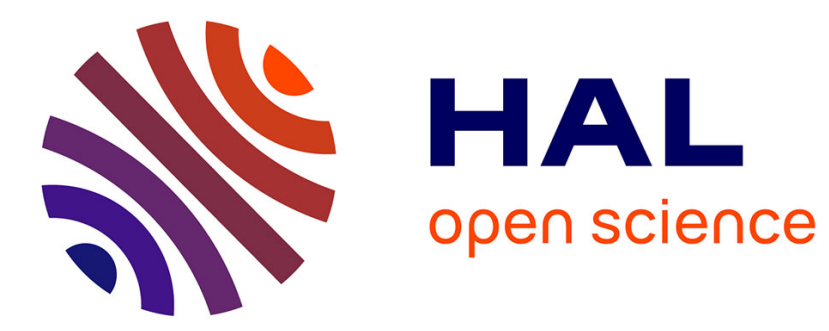

\title{
Probabilistic analysis and design at the ultimate limit state of obliquely loaded strip footings
}

\author{
Abdul-Hamid Soubra, D. S. Youssef Abdel Massih
}

\section{To cite this version:}

Abdul-Hamid Soubra, D. S. Youssef Abdel Massih. Probabilistic analysis and design at the ultimate limit state of obliquely loaded strip footings. Geotechnique, Institution of Civil Engineers, London., 2010, 60 (4), pp.275-285. 10.1680/geot.7.00031 . hal-01007200

\section{HAL Id: hal-01007200 https://hal.science/hal-01007200}

Submitted on 26 Nov 2017

HAL is a multi-disciplinary open access archive for the deposit and dissemination of scientific research documents, whether they are published or not. The documents may come from teaching and research institutions in France or abroad, or from public or private research centers.
L'archive ouverte pluridisciplinaire HAL, est destinée au dépôt et à la diffusion de documents scientifiques de niveau recherche, publiés ou non, émanant des établissements d'enseignement et de recherche français ou étrangers, des laboratoires publics ou privés. 


\title{
Probabilistic analysis and design at the ultimate limit state of obliquely loaded strip footings
}

\author{
A.-H. SOUBRA* and D. S. YOUSSEF ABDEL MASSIH†
}

This paper presents a probabilistic approach for the analysis and design of a strip footing subjected to an inclined load. Both the punching and sliding modes of failure were considered. The deterministic model of the soil punching mode was based on the kinematic approach of limit analysis using a non-symmetrical translational multiblock failure mechanism. The vertical and horizontal components of the footing load were considered as random variables. The soil shear strength parameters were first modelled as random variables and then as random fields to take into account the soil spatial variability. Spatial averaging was used to transform the random field problem to a simple problem of correlated random variables. The reliability index of each failure mode and the system failure probability were calculated. When the soil shear strength parameters were modelled as random variables, it was shown that the coefficient of variation of the angle of internal friction and that of the horizontal footing load have a non-negligible effect on the system failure probability. On the other hand, when the shear strength parameters were modelled as random fields, it was found that the case of $(a)$ a finite (i.e. noninfinite) autocorrelation distance and/or (b) an anisotropic soil regarding the autocorrelation distance, leads to a greater reliability of the foundation with respect to the reference case of isotropic and infinite autocorrelation distances (i.e. the case of random variables). For both cases of random variables or random fields, it was shown that the negative correlation between the shear strength parameters gives a greater reliability of the foundation in comparison to the uncorrelated shear strength parameters. Finally, for design, an iterative procedure was performed to determine the breadth of the footing for a target system failure probability.

KEYWORDS: anisotropy; bearing capacity; failure; footings/ foundations; limit state design/analysis; statistical analysis
Cet article présente une approche probabiliste pour l'analyse et le dimensionnement d'une fondation filante soumise à un chargement incliné. Deux modes de rupture concernant d'une part le poinçonnement du sol et d'autre part le glissement de la fondation sont considérés. Le modèle déterministe utilisé pour le mode de poinçonnement est basé sur la méthode cinématique de l'analyse limite. Un mécanisme de ruine translationnel asymétrique de type multibloc est utilisé. Les composantes verticale et horizontale de la charge de fondation sont modélisées par des variables aléatoires. La cohésion et l'angle de frottement interne du sol sont modélisés dans un premier temps par des variables aléatoires puis par des champs aléatoires afin de prendre en compte l'effet de la variabilité spatiale des propriétés du sol. La méthode de moyennage local est utilisée pour transformer les champs aléatoires en une série de variables aléatoires corrélées entre elles. L'indice de fiabilité correspondant à chaque mode de rupture et la probabilité de ruine du système poinçonnement-glissement sont déterminés. Pour le cas où les caractéristiques de cisaillement du sol sont modélisées par des variables aléatoires, il a été montré que les coefficients de variation de l'angle de frottement interne du sol et de la composante horizontale du chargement ont un effet non négligeable sur la probabilité de ruine du système. D'autre part, quand les paramètres de cisaillement du sol sont modélisés par des champs aléatoires, il a été montré que les hypothèses $(a)$ d'une distance d'autocorrélation finie, et/ou (b) d'un sol anisotrope en ce qui concerne la distance d'autocorrélation, aboutissent à une meilleure fiabilité de la fondation par rapport à celles d'un sol isotrope et ayant une distance d'autocorrélation infinie (i.e. cas des variables aléatoires). Pour les deux cas de variables et de champs aléatoires, il a été montré que la corrélation négative entre les paramètres de résistance au cisaillement aboutit à une plus grande valeur de la fiabilité de la fondation par rapport au cas de paramètres de cisaillement non corrélés. Enfin, cet article présente une procédure de dimensionnement permettant de déterminer la largeur de la fondation pour une valeur cible de la probabilité de ruine du système.

\section{INTRODUCTION}

It is well recognised that geotechnical structures such as shallow or deep foundations exhibit large variability and uncertainty in the soil parameters and sometimes in the loads (e.g. foundations of structures in harsh environments). Traditional deterministic models are based on simplified approaches in which the uncertainty and variability are taken into account through the use of a global safety factor. The

\footnotetext{
* University of Nantes, 44603 Saint-Nazaire cedex, France.

$\dagger$ CNRS \& Lebanese University, Beirut, Lebanon.
}

selection of this factor is based on engineering judgement. Nowadays, owing to improvement of our knowledge on the statistical properties of soil (Degroot \& Baecher, 1993; Popescu, 1995; Lacasse \& Nadim, 1996; Fenton, 1999; Phoon \& Kulhawy, 1999; Przewlocki, 2000 among others), more rational approaches based on the theory of reliability may be used. In these approaches, partial safety factors allow one to take into account the inherent uncertainty of the different random parameters in a more rigorous manner based on their statistical distributions. Recent engineering codes of practice (e.g. Eurocode 7) make use of this philosophy by introducing partial safety factors on loads and material parameters or resistances to achieve a target reliability index. The aim of this paper is not to determine these partial safety factors, but to assess the effects of load and 
material statistical parameters (e.g. coefficient of variation (COV) of the different uncertain parameters, correlation between these parameters and spatial variation of some soil properties) on the ultimate capacity (soil bearing capacity and footing sliding) and consequently on the reliability of an obliquely loaded strip foundation.

Several authors have investigated the reliability-based analysis of vertically loaded foundations against bearing capacity failure. Some (Low \& Phoon, 2002) have modelled the uncertain soil parameters as random variables (RV) and have used empirical formulae for the bearing capacity factors. These approaches have the advantage of being simple; however, they present some shortcomings because they are based on approximate deterministic models. Others (Cherubini, 2000) have considered the effect of the soil spatial variability by using a simplified approach. This is because no failure mechanism was used by the author. The estimation of the standard deviation reduction was based on the assumption of a priori distances for the dimensions of the potential failure mechanism. Subsequently, several authors (Griffiths et al., 2002; Fenton \& Griffiths, 2003; Popescu et al., 2005 among others) have modelled the spatially varying soil parameters more rigorously and have examined the effect of the soil spatial variability on the ultimate bearing capacity using a finite element model. However, these studies require high computation time owing to the use of Monte Carlo simulations (about 2 days for each calculation as mentioned by Fenton \& Griffiths, 2003). Also, to the authors' knowledge, there are no investigations on the reliability analysis or design of foundations subjected to an inclined load except the paper by Low \& Phoon (2002). Their analysis considers the soil shear strength parameters as random variables. It makes use of empirical formulas for the correction factors owing to load inclination. Some of these correction factors $\left(i_{\mathrm{q}}\right.$ and $i_{\mathrm{c}}$ ) were shown by Soubra et al. (2003) not to give conservative solutions. Furthermore, the method by Low \& Phoon (2002) does not allow one to take into account the spatial variation of the soil properties, the ultimate bearing capacity being only a function of the cohesion and angle of internal friction and it does not make use of a failure mechanism.

In this paper, a reliability-based analysis and design of a strip foundation of breadth $B$ resting on a cohesive and frictional soil and subjected to an inclined load is presented. Both the punching and sliding modes of failure are analysed. The vertical and horizontal components of the footing load were modelled as random variables. The uncertain soil shear strength parameters were first modelled by a simplified approach as random variables (i.e. each uncertain soil parameter was considered constant everywhere in the soil, the randomness of a soil parameter being taken into account from one simulation to another during the minimisation of the reliability index with respect to the soil uncertain parameters) and then by a more realistic approach as random fields (RF) to take into account the spatial variation of the soil properties. Unlike the most common approaches (random finite element methods), which make use of the deterministic finite element method to take into account the spatial variability of the soil properties (e.g. Griffiths et al., 2002; Fenton \& Griffiths, 2003), a deterministic limit analysis model based on a non-symmetrical multiblock failure mechanism is used here for simulation of the soil punching failure mode. This model has the advantage of being less time-consuming than the commonly used random finite element approach which requires much more computation time. It is based on the spatial averaging over one-dimensional domains (i.e. along the slip lines of the failure mechanism) of the random field. Thus, the random field problem was transformed to a simple problem of correlated random variables.
Unlike the random finite element method (e.g. Griffiths et al., 2002; Fenton \& Griffiths, 2003) which makes use of Monte Carlo simulations to search for the probability distribution of the system response, the present approach by the kinematic limit analysis method does not consider realisations based on Monte Carlo simulations and thus, cannot be considered as a true random field approach. However, it can be considered as a more realistic approach than a simple random variables method since it allows one to take into account the effect of spatial variation of a random field on the reliability index. Thus, it introduces the effect of the autocorrelation distances of a random field on the reliability index. Hence, the present random field approach is more rigorous than that considered in Cherubini (2000) in which a simplified approach was considered for the spatial averaging process of the random field. However, it is less efficient than the true random field approach in which not only the spatial averaging is considered in the analysis but also the Monte Carlo simulations which allow one to obtain the probability distribution of the system response.

After a brief description of the basic concepts of spatial averaging of random fields, reliability index and failure probability, the probabilistic models for both the bearing and sliding modes of failure and the corresponding numerical results are presented and discussed.

\section{BASIC RELIABILITY CONCEPTS}

Spatial averaging of a random field

The aim of this section is to introduce some concepts about random fields and their spatial averaging.

A two-dimensional (2D) continuous random field $Z(x, y)$ is defined by its mean value $\bar{Z}(x, y)$ and its covariance function defined as follows

$$
\begin{aligned}
\operatorname{COV}[ & {\left[\left(x_{1}, y_{1}\right), Z\left(x_{2}, y_{2}\right)\right] } \\
& =\sigma\left(x_{1}, y_{1}\right) \cdot \sigma\left(x_{2}, y_{2}\right) \cdot \rho\left[\left(x_{1}-x_{2}\right),\left(y_{1}-y_{2}\right)\right]
\end{aligned}
$$

where $\sigma$ is the standard deviation of the random field and $\rho$ is its autocorrelation function. For an isotropic field, the covariance function is a function only of the distance between any two points of the soil domain regardless of their locations. For an anisotropic field, it also depends on the relative location of the two points.

The average value of the random field over a domain $A$ is given by Vanmarcke (1983)

$$
Z_{A}=\frac{1}{A} \int_{A} Z(X) \mathrm{d} X
$$

If the random field is averaged over a one-dimensional (1D) domain as for the slip lines of the failure mechanism used in this paper (see Fig. 1), the domain $A$ will correspond to the distance $L$ of the segment along which a local average of the random field is defined. By averaging the random field over two arbitrary situated segments $L_{i}$ and $L_{j}$, two variables representing two local averages are found and a correlation may exist between these variables. This correlation is calculated by averaging the correlation between random variables at all points on both segments. It is given by

$$
\rho\left(L_{i}, L_{j}\right)=\frac{1}{L_{i} L_{j}} \int_{0}^{L_{i}} \int_{0}^{L_{j}} \rho(u) \mathrm{d} s \mathrm{~d} l
$$

where $u$ is the distance that separates any two points of the two segments $L_{i}$ and $L_{j}$. Analytical integration of equation (3) is simple only if both segments lie on one straight line 


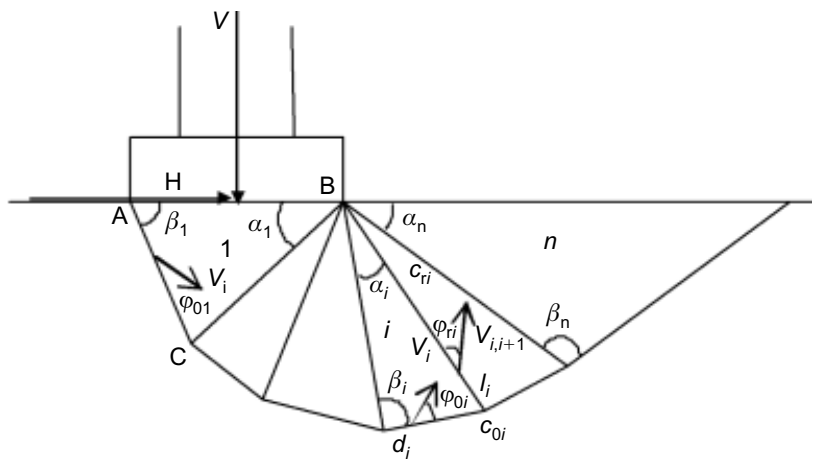

Fig. 1. Non-symmetrical translational multiblock failure mechanism - case of random fields for the soil shear strength parameters

or if all values of $\left(x_{i}-x_{j}\right)$ and $\left(y_{i}-y_{j}\right)$ are positive (Knabe et al., 1998). If the random field is assumed to be homogenous, both its expected value $\bar{Z}(x, y)$ and its standard deviation $\sigma(x, y)$ are constant for the whole field independently of the location $(x, y)$.

\section{Reliability index and failure probability}

Two different measures are commonly used in literature to describe the reliability of a structure: the reliability index and the failure probability. The widely used reliability index is the one defined by Hasofer \& Lind (1974). Its matrix formulation is given by

$$
\beta_{\mathrm{HL}}=\min _{G(x) \leqslant 0} \sqrt{\left(\frac{\boldsymbol{x}-\boldsymbol{\mu}}{\boldsymbol{\sigma}}\right)^{T}[\mathbf{R}]^{-1}\left(\frac{\boldsymbol{x}-\boldsymbol{\mu}}{\boldsymbol{\sigma}}\right)}
$$

in which $\boldsymbol{x}$ is the vector representing the random variables, $\boldsymbol{\mu}$ and $\boldsymbol{\sigma}$ are the vectors of their mean and standard deviation values and $\mathbf{R}$ is their correlation matrix. The minimisation of equation (4) is performed subject to the constraint $G(x) \leqslant 0$ where the limit state surface $G(x)=0$, separates the $n$-dimensional domain of random variables into two regions: a failure region $F$ represented by $G(x) \leqslant 0$ and a safe region given by $G(x)>0$.

The classical approach for computing $\beta_{\mathrm{HL}}$ by equation (4) is based on the transformation of the limit state surface into the space of standard normal uncorrelated variates. The shortest distance from the transformed limit state surface to the origin of the reduced variates is the reliability index $\beta_{\mathrm{HL}}$. An intuitive interpretation of the reliability index was suggested in Low \& Tang (1997) where the concept of an expanding ellipsoid led to a simple method of computing the Hasofer-Lind reliability index in the original space of the random variables for both normal and non-normal variables with or without correlation. The method of computation of the reliability index using the concept of an expanding ellipse suggested by Low \& Tang (1997) is used in this paper. From the Hasofer-Lind reliability index $\beta_{\mathrm{HL}}$, one can approximate the failure probability by using the first-order reliability method FORM as follows

$$
P_{\mathrm{f}} \approx \Phi\left(-\beta_{\mathrm{HL}}\right)
$$

where $\Phi(\cdot)$ is the cumulative distribution function (CDF) of a standard normal variable. In this method, the limit state function is approximated by a hyperplane tangent to the limit state surface at the design point.
RELIABILITY ANALYSIS OF STRIP FOUNDATIONS

For the modelling of the stochastic character of the different uncertain parameters, two cases were studied. The first case, referred to as RV, considers the cohesion $c$, the angle of internal friction $\varphi$ and the vertical and horizontal components of the applied footing load (i.e. $V$ and $H$ ) as random variables. The second case, referred to as RF, takes into account the soil spatial variability by modelling the soil shear strength parameters (i.e. $c$ and $\varphi$ ) as random fields. Both isotropic and anisotropic fields were considered in this paper. As for the RV case, the footing applied loads were taken here as random variables. The anisotropic autocorrelation function used in this paper for both the cohesion and the angle of internal friction is given by an exponential firstorder function as follows (Vanmarcke, 1983)

$$
\rho(\delta x, \delta y)=\mathrm{e}^{-2 \sqrt{\left(\frac{\delta x}{D_{\mathrm{h}}}\right)^{2}+\left(\frac{\delta y}{D_{\mathrm{v}}}\right)^{2}}}
$$

where $\left(D_{\mathrm{h}}, D_{\mathrm{v}}\right)$ are the autocorrelation distances and $(\delta x, \delta y)$ the lag distances, in the horizontal $x$ and vertical $y$ directions. A constant cross-correlation $\rho_{c, \varphi}$ between the two random fields of $c$ and $\varphi$ was used here. The other crosscorrelations $\rho_{c, \mathrm{~V}}, \rho_{\varphi, V}, \rho_{c, H}, \rho_{\varphi, H}$ and $\rho_{V, H}$ were set equal to zero.

For the probability distribution of the random variables or random fields (for which the stochastic inputs were transformed into a vector of random variables as will be seen later), two cases were studied. In the first case referred to as normal variables, $c, \varphi, V$ and $H$ were considered as normal variables. In the second case referred to as non-normal, variables, $c, V$ and $H$ were assumed to be $\log$-normally distributed while $\varphi$ was assumed to be bounded and a beta distribution was used (Fenton \& Griffiths, 2003). The parameters of the beta distribution were determined from the mean value and standard deviation of $\varphi$ (Haldar \& Mahadevan, 2000). For both cases, correlated and uncorrelated shear strength parameters were considered.

Two modes of failure may occur. These are the soil punching and the sliding of the footing along the soilfooting interface. The theoretical formulations of the probabilistic models for both modes of failure are presented in the next sections only in the RF case. The equations of the RV case are straightforward, the cohesion and the angle of internal friction being constant everywhere in the soil mass in that case.

\section{Punching mode}

The deterministic model used for the punching failure mode is based on the upper-bound method of limit analysis. A translational non-symmetrical multiblock failure mechanism is used here for the calculation of the ultimate bearing capacity (Fig. 1). This mechanism is similar in shape to that presented by Soubra (1999) for the computation of the seismic bearing capacity of strip foundations by a pseudostatic approach. It should be mentioned that this nonsymmetrical mechanism is also appropriate for the computation of the bearing capacity owing to a vertical footing load (Soubra, 1999). The present failure mechanism is composed of a sequence of $n$ triangular rigid wedges. It is described by $2 n$ angular parameters $\left[\alpha_{i}(i=1, \ldots, n)\right.$, $\left.\beta_{i}(i=1, \ldots, n)\right]$.

The present upper-bound approach is simple and selfconsistent and it obtains strict upper-bound solutions in the framework of limit analysis theory. Although the results given by this approach are upper-bound solutions and hence unconservative, they are the smallest upper-bounds against the available ones. In some cases, they are the exact 
solutions since they are equal to the results given by the lower-bound method (Soubra, 1999).

The random field has to be averaged along the different slip line segments leading to local random averages using equation (2). Thus, the stochastic inputs of a random field were transformed into a vector of random variables. In this paper, the means of the different local averages are equal to the mean of the random field, the random field being assumed homogeneous. The covariance matrix will depend on the lengths and directions of segments and on the type of random field used for the description of the stochastic character of the soil properties. Consequently, the stochastic character of the soil properties expressed by the covariance matrix may depend significantly on the potential failure mechanism. The vector of random variables $\boldsymbol{x}$ in equation (4) thus involves the local average values of the soil shear strength random fields and the random variables $V$ and $H$. Consequently, the reliability index depends on $4 n$ random variables $\left(c_{\mathrm{r} i}, \varphi_{\mathrm{r} i}, c_{\mathrm{o} j}, \varphi_{\mathrm{o} j}, V, H\right)$ where subscript o refers to slip planes on the outer boundary of the mechanism, subscript $r$ refers to radial slip planes and finally $i=1, \ldots, n-1$ and $j=1, \ldots, n$ (Fig. 1). The $4 n$ number for the random variables may be explained by the fact that the failure mechanism includes $n$ basal lines $d_{i}$ and $n-1$ radial lines $l_{i}$ over which the local averages of the cohesion and the angle of internal friction are computed. The correlation matrix $[\mathbf{R}]$ is a square matrix of dimensions $(4 n) \times(4 n)$ (Fig. 2) in which the following components can be identified.

(a) $(2 n-1)^{2}$ components were determined by equation (3) using numerical integration. Each component represents the local average correlation between two average values of the cohesion random field along two different lines of the failure mechanism; another $(2 n-1)^{2}$ components which represent the local average correlations of the angle of internal friction random field were set equal to those of the cohesion since the same correlation function was used for both $c$ and $\varphi$.

(b) Another $2 \times(2 n-1)^{2}$ components correspond to the value of the cross-correlation of the two random fields.

(c) $4 \times[2 \times(2 n-1)]$ components are the values of the cross-correlation between each of $c$ and $\varphi$ with each of $V$ and $H$ (i.e. $\rho_{c, V} ; \rho_{c, H} ; \rho_{\varphi, V} ; \rho_{\varphi, H}$ ).

(d) The last four components of the matrix [R] represent the cross-correlation $\rho_{V, H}$ and the autocorrelations (i.e. $\left.\rho_{V, V}=1 ; \rho_{H, H}=1\right)$ of the two random variables $V$ and $H$.

The numerical integration of the $2 \times(2 n-1)^{2}$ components was performed using the Gauss-Legendre quadrature method. A maximal difference of $1 \%$ was found between the $[\mathbf{R}]$-components determined using eight Gauss-points and those obtained by using 16 Gauss-points. Consequently, eight Gauss-points were used in all subsequent calculations.

The failure mechanism shown in Fig. 1 is kinematically admissible: $V_{i}$ and $V_{i, i+1}$ are respectively the velocity of block $i$ and the inter-block velocity between blocks $i$ and $i+1$ where $i=1, \ldots, n$. The first wedge ABC is translating as a rigid body with a downward velocity $V_{1}$ inclined at an angle $\varphi_{\mathrm{o} 1}$ to the discontinuity line AC. Note that the foundation is assumed to move with the same velocity as

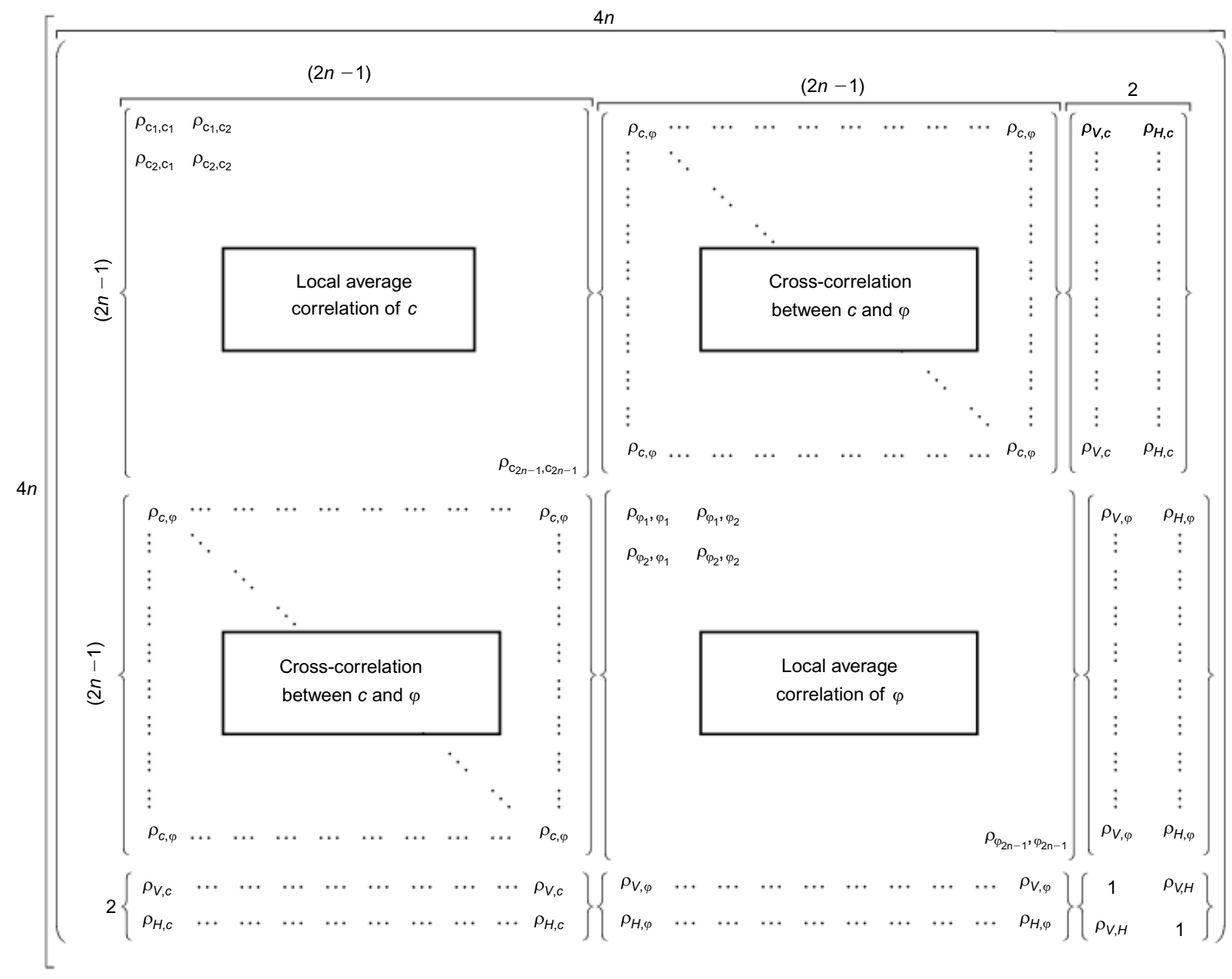

Fig. 2. Correlation matrix [R] 
that of the first block (i.e. $V_{1}$ ). The wedge $i$ is translating with a velocity $V_{i}$ inclined at $\varphi_{o i}$ to line $d_{i}$ where $\varphi_{o i}$ is the average value of the angle of internal friction along segment $d_{i}$. The inter-block velocity $V_{i, i+1}$ is inclined at $\varphi_{r i}$ to line $l_{i}$ where $\varphi_{\mathrm{r} i}$ is the average value of the angle of internal friction along segment $l_{i}$. As for the angle of internal friction, the random field of the cohesion is averaged along each segment of the mechanism; $c_{\mathrm{o} i}$ is the average value along $d_{i}$ and $c_{r i}$ is the average value along $l_{i}$.

The calculation of the ultimate bearing capacity of the footing was performed by equating the total rate of work done by the foundation load and the soil weight in motion to the total rate of energy dissipation along the lines of velocity discontinuities of the failure mechanism. It was found that an upper-bound on the bearing capacity of the spatially varying soil is given as follows

$$
R_{\mathrm{u}}=\frac{1}{2} \gamma B^{2}\left(-f_{1} / f_{0}\right)+\mu_{\mathrm{c}} B\left(f_{2}+f_{3}\right) / f_{0}
$$

in which $\mu_{\mathrm{c}}$ is the mean value of the cohesion random field and $f_{t}$ are non-dimensional functions where $t=0, \ldots 3$. These functions are expressed in terms of the geometrical parameters of the failure mechanism and the local average values of the soil shear strength random fields along the different lines of the mechanism [i.e. $f_{t}=$ $f_{t}\left(\alpha_{i}, \beta_{i}, c_{\mathrm{r} i} / \mu_{\mathrm{c}}, c_{\mathrm{o} j} / \mu_{\mathrm{c}}, \varphi_{\mathrm{r} i}, \varphi_{\mathrm{o} j}\right) \quad$ where $i=1, \ldots, n-1$ and $j=1, \ldots, n]$. The expressions of $f_{t}$ are given in the Appendix.

The performance function of the punching mode was defined with respect to the bearing capacity failure of the soil. It is given by

$$
G_{1}=\frac{R_{\mathrm{u}}}{V}-1=F_{P}-1
$$

where $R_{\mathrm{u}}$ is the vertical component of the ultimate foundation resistance and $V$ is the vertical applied footing load.

\section{Sliding mode}

For the sliding failure mode, the ultimate sliding resistance leading to the sliding of the footing can be simply calculated as

$$
S_{\mathrm{u}}=V \tan \delta+a B
$$

where $\delta$ is the angle of friction at the soil-footing interface and $a$ is the adhesion stress. The values of $a$ and $\delta$ depend on the type of the soil-footing interface. The adhesion stress $a$ was assumed to be given by the following empirical formula: $a=c_{B} \tan \delta / \tan \varphi_{B}$ which expresses the fact that the adhesion stress is equal to zero for a perfectly smooth $\left(\delta=0^{\circ}\right)$ interface and becomes equal to $c_{B}$ for a perfectly rough $\left(\delta=\varphi_{B}\right)$ interface. The illustrative value of $\delta$ was taken equal to $\delta=2 \varphi_{B} / 3$. Notice that $c_{B}$ and $\varphi_{B}$ are the values of the soil shear strength at the soil-footing interface. For the RF case, $c_{B}$ and $\varphi_{B}$ are respectively equal to the values of the cohesion and angle of internal friction of the soil averaged along the soil-footing interface.

The performance function of the sliding mode of failure is given by

$$
G_{2}=\frac{S_{\mathrm{u}}}{H}-1=F_{S}-1
$$

where $S_{\mathrm{u}}$ was defined above (equation (9)) and $H$ is the horizontal applied footing load.

For the sliding failure mode, the vector of random variables $\boldsymbol{x}$ in equation (4) involves the four random variables $(c, \varphi, V, H)$. The $4 \times 4$ correlation matrix which describes the correlation structure contains the cross and autocorrelation coefficients of the different random variables. For the
RV case, the diagonal components of $[\mathbf{R}]$ are equal to 1 and the other components correspond to the values of the correlation between the random variables $c_{B}=c, \varphi_{B}=\varphi, V$ and $H$. However, for the RF case, the matrix $[\mathbf{R}]$ differs from that of the RV case by its two diagonal components. These components were determined with the aid of equation (3) as follows

$$
\rho_{c_{B}, c_{B}}=\rho_{\varphi_{B}, \varphi_{B}}=\frac{1}{B^{2}} \int_{0}^{B} \int_{0}^{B} e^{-2\left(\frac{x_{i}-x_{j}}{D_{h}}\right)} d x_{i} d x_{j}
$$

These coefficients represent the local average autocorrelations of both $c$ and $\varphi$ along the soil-footing interface. It should be mentioned that only the horizontal autocorrelation distance was used in equation (11). This is because the segment along which the sliding at the soil-footing interface occurs is in the horizontal direction.

\section{NUMERICAL RESULTS}

The Hasofer-Lind reliability index given by equation (4) was used for the computation of the reliability of the foundation for both the punching and sliding failure modes. The minimisation of the quadratic form of this equation was performed using the constrained minimisation command 'fmincon' built in the optimization tool of Matlab 7.0 software.

The numerical results presented in this paper consider the case of a strip foundation with breadth $B=2 \mathrm{~m}$. The soil has a unit weight of $18 \mathrm{kN} / \mathrm{m}^{3}$. Different values of the coefficients of variation of the angle of internal friction and cohesion were presented in literature. For most soils, the mean value of the effective angle of internal friction is typically between $20^{\circ}$ and $40^{\circ}$. Within this range, the corresponding coefficient of variation as proposed by Phoon \& Kulhawy (1999) is essentially between $5 \%$ and $15 \%$. For the effective cohesion, the coefficient of variation varies between $10 \%$ and $70 \%$ (Cherubini, 2000). For the coefficient of correlation, Harr (1987) has shown that a correlation exists between the effective cohesion $c$ and the effective angle of internal friction $\varphi$. The results of Wolff (1985) $\left(\rho_{c, \varphi}=-0.47\right), \quad$ Yuceman et al. (1973) $\quad(-0.49 \leqslant$ $\left.\rho_{c, \varphi} \leqslant-0.24\right)$, Lumb (1970) $\left(-0.7 \leqslant \rho_{c, \varphi} \leqslant-0.37\right)$ and Cherubini (2000) $\left(\rho_{c, \varphi}=-0.61\right)$ are among the ones cited in literature. In this paper, the illustrative values used for the statistical moments of the soil shear strength parameters and their cross-correlation $\rho_{c, \varphi}$ are given as follows: $\mu_{c}=20 \mathrm{kPa}, \mu_{\varphi}=30^{\circ}, \mathrm{COV}_{c}=20 \%, \mathrm{COV}_{\varphi}=10 \%$ and $\rho_{c, \varphi}=-0 \cdot 5$. For the statistical moments of the vertical and horizontal footing applied loads, the mean values were chosen smaller than the ones corresponding to the deterministic failure loads given by the interaction diagram (see Fig. 3 ). Notice that the interaction diagram is determined for the mean values of the shear strength parameters. For the vertical load, a small coefficient of variation of $10 \%$ was considered. In contrast, the horizontal load exhibits high uncertainties (wind, earthquake, etc.). Consequently, an arbitrary large coefficient of variation of $40 \%$ was taken. The numerical results are first presented for the RV case and then for the RF case.

\section{Results of the RV case}

Probabilistic failure surface. A common approach to determine the reliability of a stressed soil mass is based on the calculation of the reliability index corresponding to the most critical deterministic surface obtained from the determination of the minimal safety factor or the ultimate load (e.g. Christian et al., 1994). In this paper, a more rigorous 


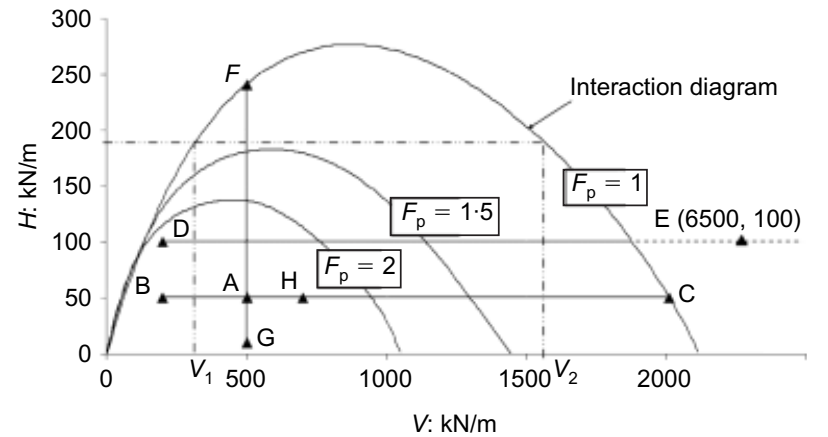

Fig. 3. Interaction diagram and the similarity in shape of curves for different values of $F_{p}$ when $\varphi=30^{\circ}$ and $c=20 \mathrm{kPa}$

approach was used. It consists in the determination of the reliability index of the punching mode by searching for the critical probabilistic surface which corresponds to minimising the quadratic form of equation (4) not only with respect to the random variables but also with respect to the geometrical parameters of the failure mechanism $\left(\alpha_{i}, \beta_{i}\right)$ where $(i=1, \ldots, n)$. The computation was performed in Fig. 4 in the case of non-normal and uncorrelated variables and for $\mu_{H}=50 \mathrm{kN} / \mathrm{m}$ and $\mu_{V}=500 \mathrm{kN} / \mathrm{m}$ (i.e. point A in Fig. 3). $n$ was taken equal to 12 in the present case since for a greater number of blocks, the improvement of the solution was not significant. This corresponds to 24 angular parameters $\alpha_{i}$ and $\beta_{i}$. Therefore, the minimisation was performed with respect to 28 parameters (24 parameters for the angular parameters of the failure mechanism and 4 parameters for the random variables $c, \varphi, V$ and $H$ ). The obtained surface corresponding to the minimum reliability index is referred to here as the critical probabilistic surface. The reliability index obtained using this surface was smaller (i.e. more critical) than the one calculated by using the critical deterministic surface (Fig. 4). Also, the two failure surfaces were found to be significantly different. The present approach of minimising the reliability index not only with respect to the random variables but also with respect to the geometrical parameters of the failure mechanism was used by Bhattacharya et al. (2003) and Low et al. (1998) among others.

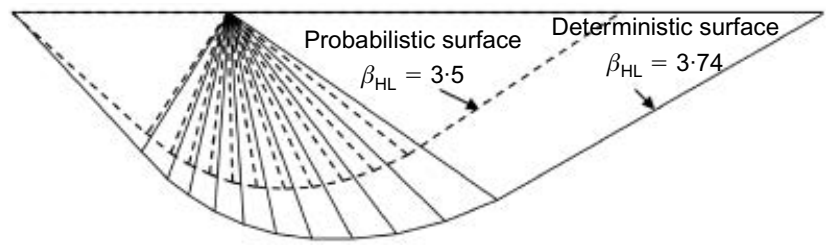

Fig. 4. Probabilistic and deterministic failure surface
Reliability indexes, design points and system failure probability. As mentioned before, two modes of failure may occur. Consequently, two values of the Hasofer-Lind reliability index corresponding to the two modes of failure were calculated. Table 1 presents the reliability results [i.e. reliability index of the two failure modes, the corresponding design points $\left(c^{*}, \varphi^{*}, V^{*}, H^{*}\right)$ and the system failure probability $\left.P_{\text {fsys }}\right]$ for different values of the mean vertical applied load $\mu_{V}$ and for a given prescribed value of the mean horizontal applied load $\mu_{H}=50 \mathrm{kN} / \mathrm{m}$. This corresponds to segment BC in Fig. 3. Non-normal and uncorrelated variables were considered. The system failure probability under the two failure modes involving sliding and punching is given by

$$
P_{\text {fsys }}=P_{\mathrm{f}}(P \cup S)=P_{\mathrm{f}}(P)+P_{\mathrm{f}}(S)-P_{\mathrm{f}}(P \cap S)
$$

where $P_{\mathrm{f}}(P)$ and $P_{\mathrm{f}}(S)$ are the failure probabilities under the punching and sliding failure modes respectively and $P_{\mathrm{f}}(P \cap S)$ is the failure probability under the punching and sliding failure modes. The failure probability of the intersection is given as follows (Lemaire, 2005)

$$
\max (P(A), P(B)) \leqslant P_{f}(P \cap S) \leqslant P(A)+P(B)
$$

where

$$
\begin{aligned}
& P(A)=\Phi\left(-\beta_{P}\right) \Phi\left(-\frac{\beta_{S}-\rho_{\mathrm{PS}} \beta_{P}}{\sqrt{1-\rho_{\mathrm{PS}}^{2}}}\right) \\
& P(B)=\Phi\left(-\beta_{S}\right) \Phi\left(-\frac{\beta_{P}-\rho_{\mathrm{PS}} \beta_{S}}{\sqrt{1-\rho_{\mathrm{PS}}^{2}}}\right) \\
& \rho_{P S}=\left\langle\alpha_{P}\right\rangle\left\{\alpha_{S}\right\}
\end{aligned}
$$

$\beta_{P}$ and $\beta_{S}$ are the reliability indexes corresponding to the punching and sliding failure modes respectively and $\rho_{P S}$ is the correlation between the two failure modes where $\alpha_{\mathrm{P}}$ and $\alpha_{\mathrm{S}}$ for both modes can be computed as follows

$$
\alpha_{i}=-\left.\frac{\partial \beta}{\partial u_{i}}\right|_{\left\{u^{*}\right\}}=-\frac{u_{i}^{*}}{\beta}
$$

In equation (17), $\beta$ is the reliability index and $u_{i}{ }^{*}$ is the standard uncorrelated normal variable at the design point.

The system reliability index can be approximated using the FORM approximation as follows

$$
\beta_{\mathrm{sys}}=-\Phi^{-1}\left(P_{\mathrm{fsys}}\right)
$$

\begin{tabular}{|c|c|c|c|c|c|c|c|c|c|c|c|c|}
\hline \multirow[t]{2}{*}{$\mu_{V}: \mathrm{kN} / \mathrm{m}$} & \multicolumn{5}{|c|}{ Punching mode reliability } & \multicolumn{5}{|c|}{ Sliding mode reliability } & \multicolumn{2}{|c|}{ System reliability } \\
\hline & $c^{*}: \mathrm{kPa}$ & $\varphi^{*}:^{\circ}$ & $\begin{array}{c}H^{*}: \\
\mathrm{kN} / \mathrm{m}\end{array}$ & $V^{*}: \mathrm{kN} / \mathrm{m}$ & $\beta_{\mathrm{HL}}$ & $c^{*}: \mathrm{kPa}$ & $\varphi^{*}:^{\circ}$ & $\begin{array}{c}H^{*}: \\
\mathrm{kN} / \mathrm{m}\end{array}$ & $V^{*}: \mathrm{kN} / \mathrm{m}$ & $\beta_{\mathrm{HL}}$ & $P_{\text {fsys }}: \%$ & $\beta_{\text {sys }}$ \\
\hline 200 & $17 \cdot 6$ & $27 \cdot 9$ & $131 \cdot 2$ & $191 \cdot 2$ & $2 \cdot 87$ & $18 \cdot 7$ & 28.9 & $91 \cdot 0$ & $192 \cdot 5$ & $1 \cdot 83$ & $3 \cdot 36$ & $1 \cdot 83$ \\
\hline 300 & $16 \cdot 8$ & $26 \cdot 7$ & $151 \cdot 6$ & 288.4 & $3 \cdot 37$ & $18 \cdot 7$ & $28 \cdot 2$ & $120 \cdot 4$ & $283 \cdot 6$ & $2 \cdot 61$ & 0.46 & $2 \cdot 61$ \\
\hline 400 & 15.9 & $25 \cdot 1$ & $148 \cdot 4$ & $393 \cdot 0$ & $3 \cdot 58$ & $18 \cdot 7$ & $27 \cdot 7$ & $148 \cdot 3$ & $372 \cdot 8$ & $3 \cdot 19$ & $0 \cdot 08$ & $3 \cdot 17$ \\
\hline 500 & $14 \cdot 7$ & $22 \cdot 5$ & $98 \cdot 2$ & $522 \cdot 2$ & $3 \cdot 51$ & $18 \cdot 7$ & $27 \cdot 3$ & $175 \cdot 1$ & $460 \cdot 7$ & $3 \cdot 65$ & $0 \cdot 03$ & $3 \cdot 39$ \\
\hline 600 & $14 \cdot 9$ & $22 \cdot 4$ & $67 \cdot 7$ & $641 \cdot 9$ & $3 \cdot 15$ & $18 \cdot 7$ & $26 \cdot 9$ & $201 \cdot 0$ & $547 \cdot 5$ & $4 \cdot 04$ & $0 \cdot 09$ & $3 \cdot 14$ \\
\hline 700 & $15 \cdot 5$ & $23 \cdot 0$ & $59 \cdot 2$ & $746 \cdot 8$ & $2 \cdot 77$ & $18 \cdot 8$ & $26 \cdot 5$ & $226 \cdot 1$ & $633 \cdot 5$ & $4 \cdot 38$ & $0 \cdot 28$ & $2 \cdot 77$ \\
\hline 1300 & $18 \cdot 0$ & $27 \cdot 0$ & $48 \cdot 5$ & $1333 \cdot 1$ & $1 \cdot 14$ & $18 \cdot 9$ & $25 \cdot 1$ & $365 \cdot 8$ & $1136 \cdot 7$ & $5 \cdot 75$ & $12 \cdot 75$ & $1 \cdot 14$ \\
\hline 1700 & $19 \cdot 0$ & $28 \cdot 8$ & $47 \cdot 0$ & $1710 \cdot 6$ & 0.43 & $19 \cdot 0$ & $24 \cdot 4$ & $451 \cdot 8$ & $1464 \cdot 2$ & $6 \cdot 36$ & $33 \cdot 26$ & 0.43 \\
\hline 2010 & $19 \cdot 6$ & $30 \cdot 0$ & $46 \cdot 4$ & $2089 \cdot 6$ & 0.00 & $19 \cdot 0$ & $23 \cdot 8$ & $533 \cdot 7$ & $1787 \cdot 4$ & 6.84 & $50 \cdot 00$ & $0 \cdot 00$ \\
\hline
\end{tabular}

For a prescribed value of the horizontal load and for small values of the vertical footing load, the sliding mode is most likely to occur and no punching mode is expected. In these

Table 1. Reliability results for different values of the mean vertical applied load 
cases, the punching reliability index increases with increase of $\mu_{V}$ since an increase of $\mu_{V}$ increases the stability of the footing against punching. This is because, for small values of the vertical applied load, the increase in the vertical load component counterbalances the punching effect of the applied loads. In contrast, for higher values of the vertical footing load, the punching mode becomes the most critical mode of failure. A $\mu_{V}$-increase decreases the punching reliability index. These observations explain why the punching reliability index first increases and then decreases with the vertical footing load $\mu_{V}$ for a prescribed value of the horizontal load. Concerning the sliding reliability index, it continuously increases with $\mu_{V}$ since the resisting force in the sliding performance function continuously increases with $\mu_{V}$

The value of the system reliability index is very close to the minimum value of the two modes (see last column in Table 1). Hence, only a single mode of failure is predominant in the computation of the failure probability of the system. For small values of the footing vertical load, the sliding mode is dominant. When this vertical component increases, the punching mode becomes more critical. The value of $H^{*}$ increases in the sliding mode with the increase of $\mu_{V}$. This is because when the vertical applied load increases a higher $H$ is needed to reach sliding failure. For the punching mode, when the sliding mode is predominant (i.e. for small values of $\mu_{V}$ ), $H^{*}$ behaves in the same way as for the sliding mode (i.e. increases). However, it decreases when the punching mode dominates.

Figure 5 presents the variation of the system failure probability with the dimensionless vertical applied load $\mu_{V} /\left(\gamma B^{2}\right)$ when $\mu_{H}=100 \mathrm{kN} / \mathrm{m}$. This corresponds to segment DE in Fig. 3. Non-normal and uncorrelated variables were considered. It can be seen from Fig. 5 that the failure probability decreases with increase of the mean vertical applied load when $\mu_{V}$ is small compared to $\mu_{H}$ and increases for higher values of $\mu_{V}$. As mentioned before, two regions were detected: a zone where sliding dominates and another one where punching is the most critical.

Effect of correlation on the reliability index. Figures 6 and 7 show the variation of the reliability index with the safety factor for the punching and sliding modes. For the punching failure mode (Fig. 6), a constant horizontal force of $50 \mathrm{kN} / \mathrm{m}$ was applied to the footing and the vertical load was varied from point $\mathrm{C}$ to point $\mathrm{B}$ as shown in Fig. 3. However, for the sliding failure mode (Fig. 7), a constant vertical load of $500 \mathrm{kN} / \mathrm{m}$ was applied and the horizontal load was varied from point $F$ to point $G$ (Fig. 3). The cases of normal and

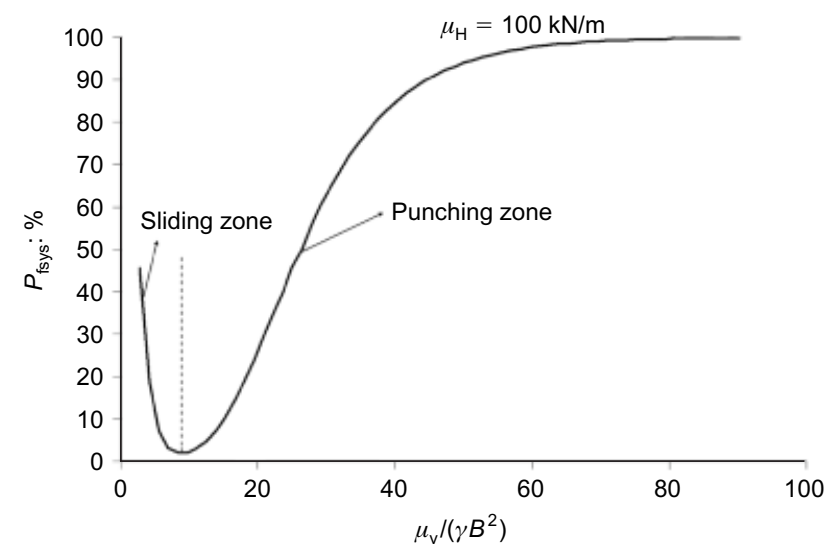

Fig. 5. System failure probability $P_{\mathrm{f}_{s y s}}$ against $\mu_{V} /\left(\gamma B^{2}\right)$

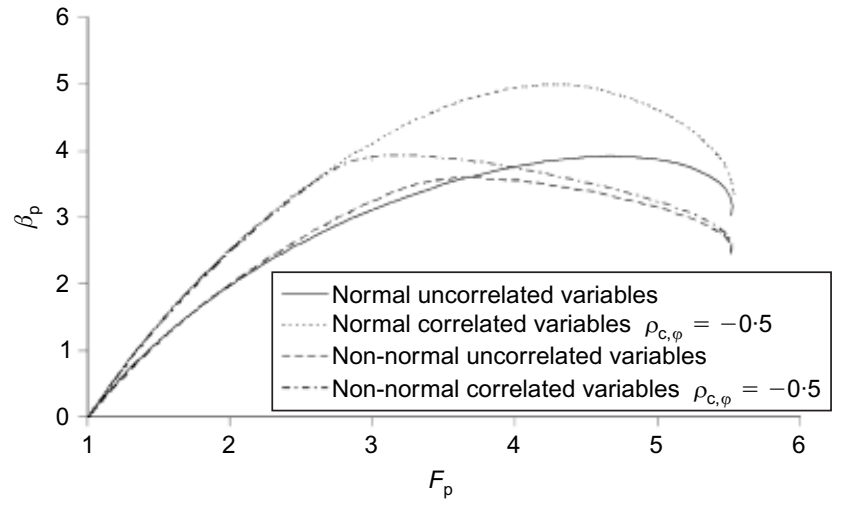

Fig. 6. Reliability index against safety factor for punching mode

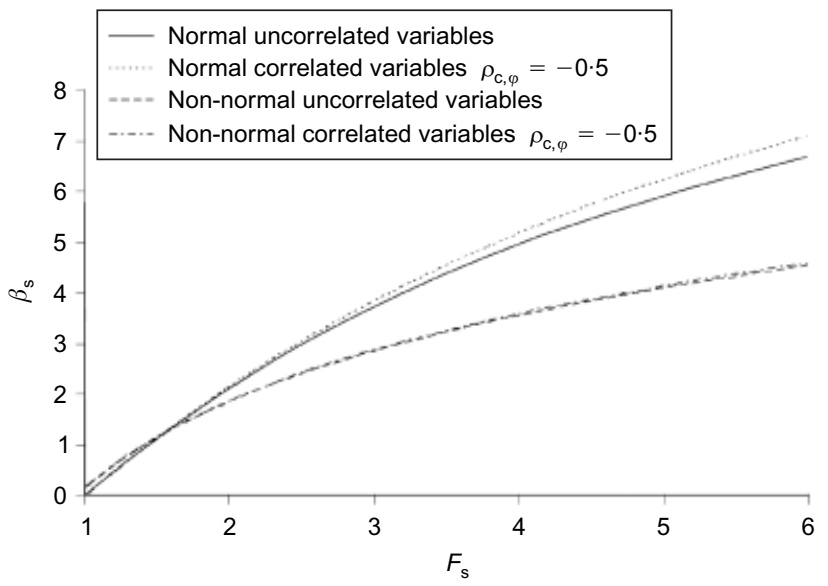

Fig. 7. Reliability index against safety factor for sliding mode

non-normal variables with or without correlation between the shear strength parameters were considered. As shown in Figs 6 and 7, the reliability index corresponding to uncorrelated shear strength parameters is smaller than the one of negatively correlated variables for both normal and nonnormal probability distributions (Mostyn \& Li, 1993). The difference is most significant for the punching mode. From Fig. 6 , it can be seen that for large $\beta_{P}$-values $\left(\beta_{\mathrm{P}}>3\right)$ for which sliding is not predominant; each $\beta_{P}$ corresponds to two different values of the punching safety factor $F_{p}$. This may be explained with the aid of the interaction diagram $\left(F_{p}=1\right)$ and the similarity in shape of curves corresponding to different values of $\left(F_{p}\right)$ since all these curves give two values of the vertical load $\left(V_{1}\right.$ and $\left.V_{2}\right)$ for a prescribed value of the horizontal load (Fig. 3).

Effect of the variability of each random variable on the CDF of the punching and sliding safety factors. The probability distribution of the safety factors of the footing is influenced by the variability of the soil shear strength parameters used in the probabilistic analysis. Since correlated variables are used in this paper, the sensitivity factors $\alpha_{i}$ defined with respect to the transformed standard uncorrelated variables $u$ as $\alpha_{i}=\delta \beta / \delta u$ have no physical meaning (Melchers, 1999, p.101).

Figures 8 and 9 show the effect of the coefficient of variation of each random variable on the CDFs of the punching and sliding safety factors. Five cases were considered. The first case, referred to as 'reference case', considers the statistical moments given in the introduction of the section named 'Numerical results' with $\mu_{V}=500 \mathrm{kN} / \mathrm{m}$ and 


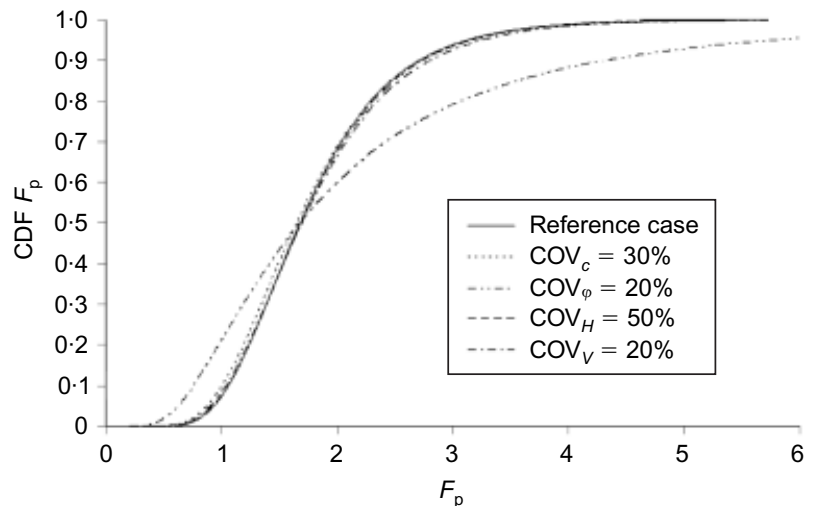

Fig. 8. CDFs of the punching safety factor

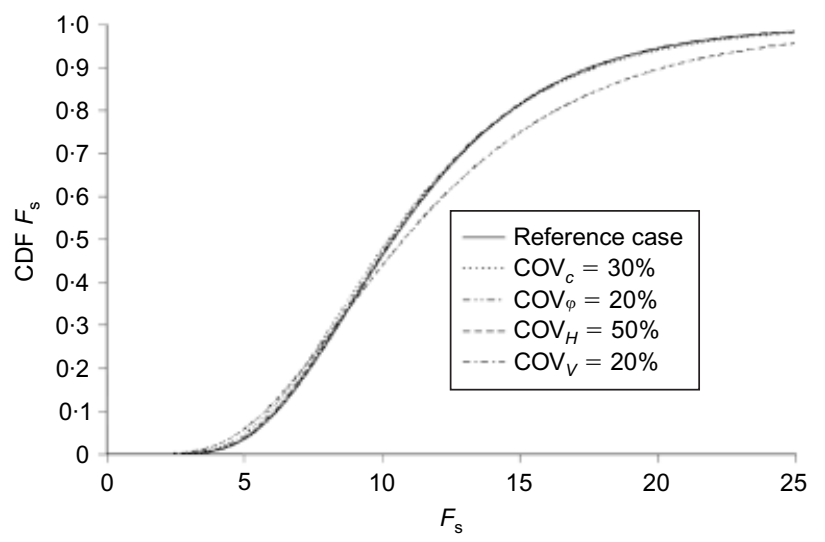

Fig. 9. CDFs of the sliding safety factor

$\mu_{H}=50$ (i.e. point A in Fig. 3). The other cases correspond to an increase by $10 \%$ of the coefficient of variation of each variable. Non-normal and correlated variables were considered. It can be seen that a small variation of the coefficient of variation of $\varphi$ significantly affects the CDF curve of the punching safety factor. One can also notice that the CDF curve is slightly sensitive to a variation of the other variables' uncertainty. This may be explained as follows: For $\mu_{\varphi}=30^{\circ}$, a variation by $10 \%$ in $\operatorname{COV}_{\varphi}$ will result in a variation of $\varphi$ between $27^{\circ}$ and $33^{\circ}$ which will greatly affect the value of the ultimate capacity and consequently results in a high variation in the failure probability. Concerning the CDF curve of the sliding safety factor, it is significantly affected by a small variation of $\mathrm{COV}_{H}$ since a small variation in $H$ greatly affects the footing sliding stability.

As a conclusion, the system failure probability is highly influenced by the coefficients of variation of $\varphi$ and $H$. Thus, the accurate determination of the uncertainties of the angle of internal friction $\varphi$ and the horizontal footing load $H$ is very important in obtaining reliable probabilistic results. In contrast, the coefficients of variation of $c$ and $V$ do not significantly affect the failure probability.

Probabilistic design. The conventional deterministic approach used in the design of a shallow foundation consists in prescribing target safety factors (generally $F_{\mathrm{p}}=3$ for the punching mode and $F_{\mathrm{s}}=1.5$ for the sliding mode) and determining the corresponding breadth of the footing $B$. In this section, a probabilistic design is presented. It consists in the calculation of $B$ for a system target reliability index of 3.8. Note that this value is that suggested in the head Eurocode (EN 1990:2002 - Eurocode: Basis of Design) upon which Eurocode 7 and the other Eurocodes are based (Orr \&
Breysse, 2008). This value of 3.8 is that of the ultimate limit state and corresponds to the 50-year minimum target reliability index. The mean values of the applied loads were taken equal to $\mu_{V}=500 \mathrm{kN} / \mathrm{m}$ and $\mu_{H}=50 \mathrm{kN} / \mathrm{m}$ (i.e. point A in Fig. 3). Fig. 10 presents the probabilistic foundation breadth for different values of the coefficients of variation of the random variables and for different values of the coefficient of correlation of the shear strength parameters. The case of non-normal variables is considered. This figure also presents the deterministic breadth corresponding to a punching safety factor of 3 for which the sliding safety factor was checked to be higher than $1 \cdot 5$. Since it was shown in the previous section that the accurate determination of the uncertainties of the angle of internal friction $\varphi$ and the footing horizontal load is very important in obtaining reliable probabilistic results, only the effect of the coefficients of variation of these variables on the probabilistic breadth was presented. From Fig. 10, one can notice that the probabilistic foundation breadth decreases with the increase of the negative correlation between the shear strength parameters and the decrease of the coefficients of variation of the random variables. It can become smaller than the deterministic breadth for small values of the coefficient of variation of the horizontal load and for the common values of the soil variability (i.e. $\operatorname{COV}_{\varphi}=5-10 \%, \operatorname{COV}_{c}=20 \%,-0.7 \leqslant$ $\left.\rho_{c, \varphi} \leqslant-0 \cdot 3\right)$. For large values of the coefficients of variation and small correlation coefficient, the probabilistic breadth is greater than the deterministic one. As a conclusion, the deterministic footing breadth is greater or smaller than the probabilistic one according to the values of the uncertainties. Contrary to Eurocode 7 which prescribes constant values for the material or resistance and load factors, the present reliability-based design (RBD) has the advantage of providing different values of these factors depending on the soil variability. These factors are the optimal ones and are determined by a maximisation of the failure probability for a given soil variability.

\section{Results of the RF case}

Probabilistic failure surface. When the soil shear strength parameters were considered as random fields, the determination of the critical probabilistic surface was obtained by minimising the quadratic form of equation (4) with respect to the values of the local averages of the shear strength parameters, the footing load components and the geometrical parameters of the failure mechanism. Thus, the minimisation was performed with respect to $6 n$ parameters [(a) $4 n-2$ random variables which are the local averages values of the cohesion and the angle of internal friction, (b) two random

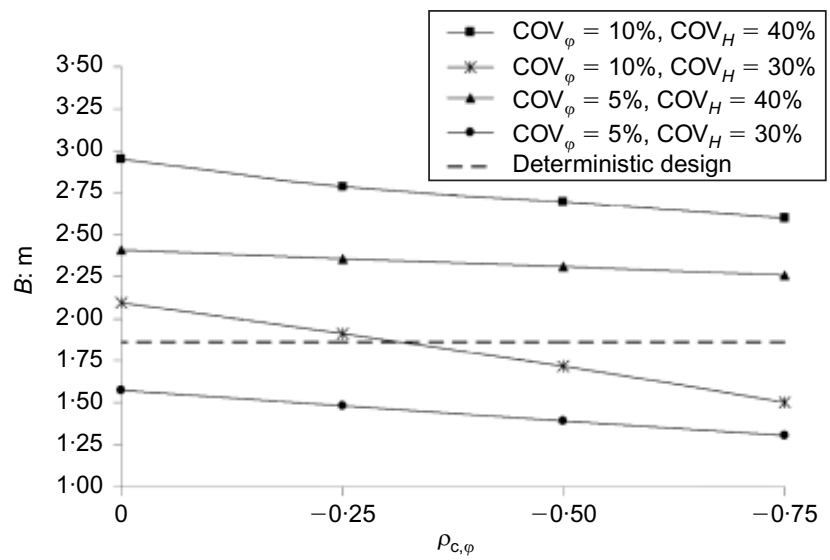

Fig. 10. Comparison between deterministic and probabilistic design 
variables which are the footing load components and, (c) the $2 n$ geometrical parameters of the failure mechanism], i.e. 60 parameters in the present case where $n=10$. Note that $n=10$ was found sufficient to give accurate results for the punching reliability index. A greater number of blocks does not improve $\beta_{\mathrm{HL}}$ by more than $0 \cdot 2 \%$. Note that the correlation matrix $[\mathbf{R}]$ of dimensions $40 \times 40$ should be calculated for each function evaluation during the minimisation process. This is because of the change in the potential failure mechanism. Each function evaluation requires $(2 n-1)^{2}=19 \times 19=361$ numerical integrations. Thus, this approach leads to a much higher computation time than calculating the reliability index using the deterministic surface. The calculation time required to perform the minimisation process by searching for the critical probabilistic surface was about 3 to 4 hours for 10 blocks on a Centrino $2.0 \mathrm{GHz}$ computer. Note that the random finite element method requires about 2 days for each calculation (see Fenton \& Griffiths, 2003).

Effect of the autocorrelation distances on the reliability index. The values of the autocorrelation distances $D_{\mathrm{h}}$ and $D_{\mathrm{v}}$ in the horizontal and vertical directions are in the range of 2 to $100 \mathrm{~m}$ for $D_{\mathrm{h}}$ and $0 \cdot 1$ to $5 \mathrm{~m}$ for $D_{\mathrm{v}}$ (Mostyn \& Li, 1993).

Figures 11 and 12 show the variation of the reliability index with the safety factor for the punching and sliding modes for different values of the autocorrelation distances. For the punching failure mode (Fig. 11), a constant horizontal force of $50 \mathrm{kN} / \mathrm{m}$ was applied to the footing and the vertical load was varied from point $\mathrm{C}$ to point $\mathrm{B}$ as shown

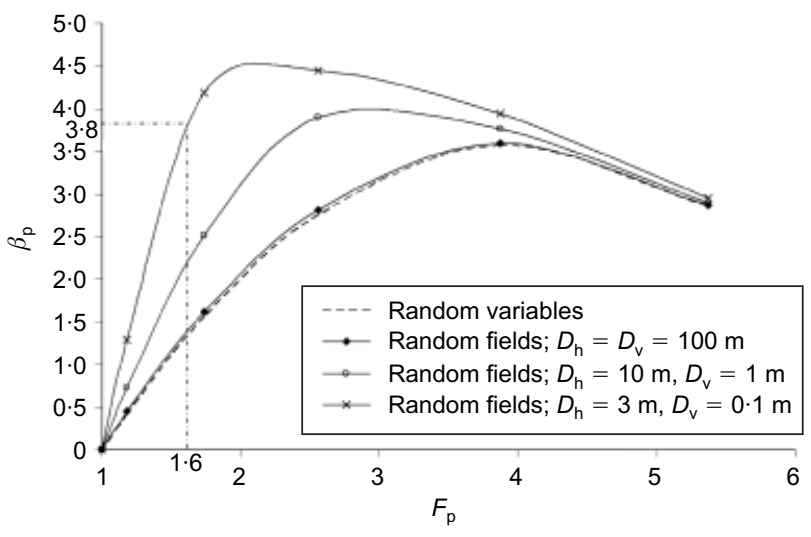

Fig. 11. Reliability index plotted against safety factor for punching mode

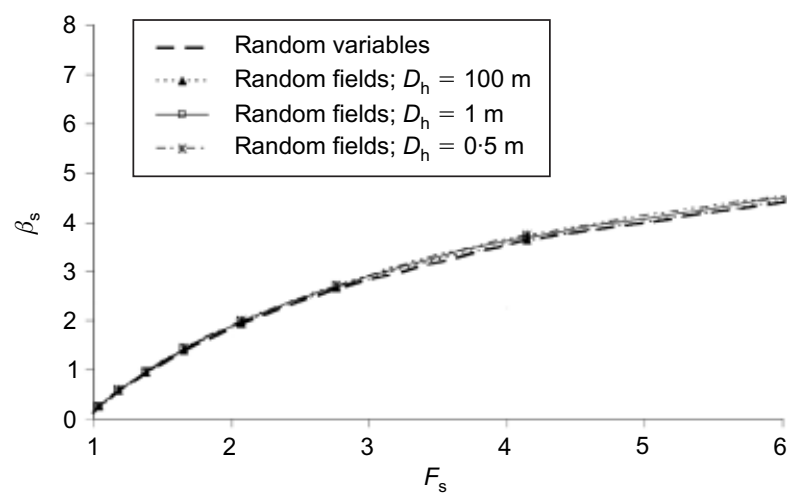

Fig. 12. Reliability index plotted against safety factor for sliding mode in Fig. 3. However, for the sliding failure mode (Fig. 12), a constant vertical load of $500 \mathrm{kN} / \mathrm{m}$ was applied and the horizontal load was varied from point $F$ to point $G$ (see Fig. 3 ). The case of non-normal shear strength random fields and non-normal horizontal and vertical applied loads, without cross-correlation between all random parameters, was considered.

For the punching mode, it can be seen from Fig. 11 that for large $\beta_{P}$-values $\left(\beta_{P}>3\right)$ for which sliding is not predominant; each $\beta_{P}$ corresponds to two different values of the punching safety factor $F_{\mathrm{p}}$. This result is similar to the one found in the RV case. It can also be observed that, for a given safety factor, the punching reliability index decreases with the increase of the autocorrelation distances and it tends, for large values of $D_{\mathrm{v}}=D_{\mathrm{h}}$, to the result obtained in the RV case. For a highly varying soil property corresponding to small values of $D_{\mathrm{v}}$ and $D_{\mathrm{h}}$, one obtains a higher reliability index with respect to the one corresponding to very great values of $D_{\mathrm{v}}$ and $D_{\mathrm{h}}$ (i.e. the case of random variable with infinite autocorrelation distances). This is in conformity with the results of Fenton \& Griffiths (2003). With respect to the conventional safety factor commonly used in practice (i.e. $F_{p}=3$ ), a lower value of 1.6 could be acceptable for $D_{\mathrm{v}}=0.1 \mathrm{~m}$ and $D_{\mathrm{h}}=3 \mathrm{~m}$ since one obtains in these cases a reliability index value equal to the practical prescribed value of 3.8 required by Eurocode for the ultimate states (Fig. 11).

For the sliding mode, it can be observed from Fig. 12 that the horizontal autocorrelation distance (which is the only distance that may affect the sliding mode) has a minor effect on the value of the sliding reliability index.

Influence of the anisotropy of the soil shear strength random fields. Figure 13 shows the variation of the system reliability index with the ratio $D_{\mathrm{v}} / D_{\mathrm{h}}$ for different values of $D_{\mathrm{h}}$ varying between 1 and $100 \mathrm{~m}$ when $\mu_{\mathrm{V}}=700 \mathrm{kN} / \mathrm{m}$ and $\mu_{\mathrm{H}}=$ $50 \mathrm{kN} / \mathrm{m}$ (i.e. point $\mathrm{H}$ in Fig. 3). Non-normal uncorrelated uncertain parameters were considered. One can conclude from this figure that for the practical case $D_{\mathrm{v}} / D_{\mathrm{h}}<1$ for which the autocorrelation distance in the vertical direction is lower than that in the horizontal direction, the reliability index is underestimated if the calculation is performed using the assumption of isotropic fields (i.e. $D_{\mathrm{v}} / D_{\mathrm{h}}=1$ ). This conclusion is in conformity with the results found in literature (Sivakumar Babu \& Mukesh, 2004). When both autocorrelation distances increase greatly, the reliability index tends to the value corresponding to the assumption of random variables. A value of 2.81 for the system reliability index was found when $D_{\mathrm{v}}=D_{\mathrm{h}}=100 \mathrm{~m}$ which is close to the value of 2.77 obtained for the RV case (Table 1 for $\mu_{\mathrm{V}}=700 \mathrm{kN} / \mathrm{m}$ ).

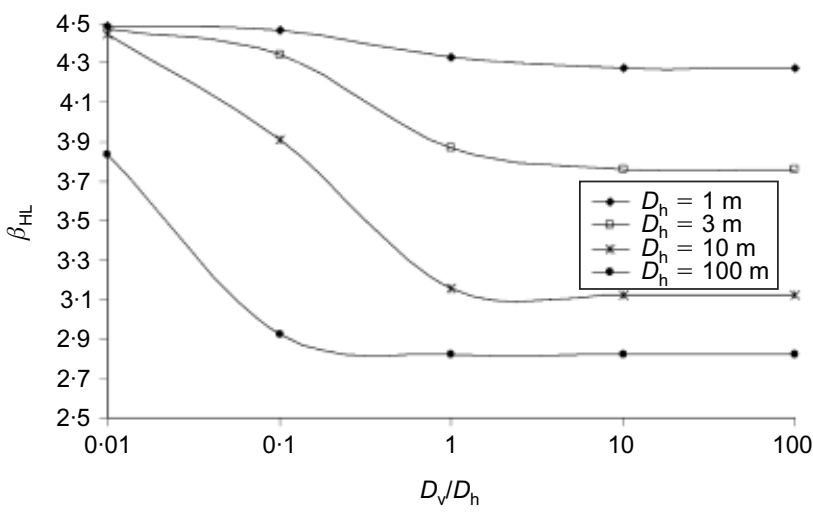

Fig. 13. System reliability index plotted against $D_{\mathrm{v}} / D_{h}$ for different values of $D_{h}$ 


\section{CONCLUSION}

This paper presents a reliability-based approach for the analysis and design of a shallow strip footing subjected to an inclined load. Both the punching and sliding modes of failure were considered. The vertical and horizontal components of the applied footing load were modelled as random variables. The soil shear strength parameters were first modelled as random variables and then as random fields. The main conclusions of this paper can be summarised as follows.

For the case where the soil properties were modelled as random variables, the following conclusions can be made.

(a) The reliability index of the punching mode determined using the critical probabilistic surface is smaller (i.e. more critical) than the one based on the critical deterministic surface.

(b) Only a single mode of failure is predominant in the computation of the failure probability of the system. For small values of the vertical footing load, the sliding mode is dominant. When this vertical component increases, the punching mode becomes more critical.

(c) The reliability index corresponding to uncorrelated shear strength parameters was found to be smaller than the one corresponding to negatively correlated variables for both normal and non-normal probability distributions.

(d) For large $\beta_{P}$-values $\left(\beta_{P}>3\right)$ for which sliding is not predominant, each $\beta_{P}$ corresponds to two different values of the punching safety factor $F_{p}$. This was explained with the aid of the interaction diagram (corresponding to $F_{p}=1$ ) and the similarity in shape of curves corresponding to different values of $F_{p}$.

(e) The system failure probability was highly influenced by the coefficients of variation of $\varphi$ and $H$. Thus, the accurate determination of the uncertainties of the angle of internal friction $\varphi$ and the horizontal footing load $H$ is very important in obtaining reliable probabilistic results.

( $f$ ) The probabilistic foundation breadth decreases with increase of the negative correlation between the shear strength parameters and decrease of the coefficients of variation of the random variables. It can become smaller than the deterministic breadth for small values of the coefficient of variation of the horizontal load and for typical values of soil variability.

(g) Contrary to Eurocode 7 which prescribes constant values for the material or resistance and load factors, the present RBD has the advantage of providing different values of these factors depending on the soil and footing load variabilities. These factors are the optimal ones and were determined by a maximisation of the failure probability for given soil and footing load variabilities.

For the case where the soil properties were modelled as random fields, the following conclusions can be made.

(a) For a given safety factor, the punching reliability index decreases with increase of the autocorrelation distances and tends, for large values of the autocorrelation distances, to the value obtained in the RV case. For the sliding mode, the horizontal autocorrelation distance has a minor effect on the value of the sliding reliability index.

(b) For the practical anisotropic case (i.e. $D_{\mathrm{v}} / D_{\mathrm{h}}<1$ ) for which the autocorrelation distance in the vertical direction is smaller than that in the horizontal direction, the reliability index is underestimated if calculation is performed using the assumption of isotropic fields (i.e. $\left.D_{\mathrm{v}} / D_{\mathrm{h}}=1\right)$

\section{APPENDIX}

The distances $l_{i}$ and $d_{i}$ of block $i$ in the failure mechanism shown in Fig. 1 are given by

$$
\begin{aligned}
& l_{i}=B \cdot \prod_{j=1}^{i} \frac{\sin \beta_{j}}{\sin \left(\alpha_{j}+\beta_{j}\right)} \\
& d_{i}=B \cdot \frac{\sin \alpha_{i}}{\sin \beta_{i}} \cdot \prod_{j=1}^{i} \frac{\sin \beta_{j}}{\sin \left(\alpha_{j}+\beta_{j}\right)}
\end{aligned}
$$

The non-dimensional functions $f_{t}(t=0,1,2,3)$ used in equation (7) of the ultimate bearing capacity are given as follows

$$
\begin{aligned}
& f_{0}=\sin \left(\beta_{1}-\varphi_{o 1}\right)+H / V \cos \left(\beta_{1}-\varphi_{o 1}\right) \\
& f_{1}=\sum_{i=1}^{n}\left[\frac{\sin \alpha_{i} \cdot \sin \beta_{i}}{\sin \left(\alpha_{i}+\beta_{i}\right)} \cdot \sin \left(\beta_{i}-\varphi_{o i}-\sum_{j=1}^{i-1} \alpha_{j}\right) \cdot \prod_{j=1}^{i-1} \frac{\sin ^{2} \beta_{j}}{\sin ^{2}\left(\alpha_{j}+\beta_{j}\right)} \cdot \frac{\sin \left(\alpha_{j}+\beta_{j}-\varphi_{r j}-\varphi_{o j}\right)}{\sin \left(\beta_{j+1}-\varphi_{r j}-\varphi_{o(j+1)}\right)}\right] \\
& f_{2}=\frac{1}{\mu_{c}} \sum_{i=1}^{n}\left[c_{o i} \cos \varphi_{o i} \cdot \frac{\sin \alpha_{i}}{\sin \left(\alpha_{i}+\beta_{i}\right)} \cdot \prod_{j=1}^{i-1} \frac{\sin \beta_{j}}{\sin \left(\alpha_{j}+\beta_{j}\right)} \cdot \frac{\sin \left(\alpha_{j}+\beta_{j}-\varphi_{\mathrm{r} j}-\varphi_{\mathrm{o} j}\right)}{\sin \left(\beta_{j+1}-\varphi_{\mathrm{r} j}-\varphi_{\mathrm{o}(j+1)}\right)}\right] \\
& f_{3}=\frac{1}{\mu_{c}} \sum_{i=1}^{n-1}\left[c_{\mathrm{r} i} \cos \varphi_{\mathrm{r} i} \cdot \frac{\sin \beta_{i}}{\sin \left(\alpha_{i}+\beta_{i}\right)} \cdot \frac{\sin \left(\beta_{i}-\beta_{i+1}+\alpha_{i}-\varphi_{\mathrm{o} i}+\varphi_{\mathrm{o}(i+1)}\right)}{\sin \left(\beta_{i+1}-\varphi_{\mathrm{r} i}+\varphi_{\mathrm{o}(i+1)}\right)} \prod_{j=1}^{i-1} \frac{\sin \beta_{j}}{\sin \left(\alpha_{j}+\beta_{j}\right)} \cdot \frac{\sin \left(\alpha_{j}+\beta_{j}-\varphi_{\mathrm{r} j}-\varphi_{\mathrm{o} j}\right)}{\sin \left(\beta_{j+1}-\varphi_{\mathrm{r} j}-\varphi_{\mathrm{o}(j+1)}\right)}\right]
\end{aligned}
$$

\section{NOTATION}

$$
\begin{aligned}
a & \text { adhesion stress } \\
A & \text { domain under which averaging is performed } \\
B & \text { breadth of the footing } \\
c & \text { cohesion of the soil } \\
\left(c^{*}, \varphi^{*}, V^{*}, H^{*}\right) & \text { design point } \\
c_{B}, \varphi_{B} & \text { soil shear strength at the soil-footing interface } \\
D_{\mathrm{h}}, D_{\mathrm{v}} & \text { horizontal and vertical autocorrelation distances } \\
\mathrm{d} s, \mathrm{~d} l & \begin{array}{l}
\text { elementary segments along } L_{i} \text { and } L_{j} \\
\text { respectively }
\end{array} \\
f_{0}, f_{1}, f_{2}, f_{3} & \text { non-dimensional functions }
\end{aligned}
$$

$F_{P}, F_{S}$ punching and sliding safety factors

$G(x)$ performance function

$i_{\mathrm{q}}, i_{\mathrm{c}}$ correction factors in bearing capacity formula for surcharge and cohesion respectively

$L$ distance along which averaging is performed

$l_{i}, d_{i}$ radial and basal lines of block $i$

$L_{i}, L_{j} \quad$ two arbitrary situated segments

$n$ number of triangular rigid wedges in the failure mechanism

$P_{\mathrm{f}} \quad$ failure probability

$P_{\mathrm{f}}(P), P_{\mathrm{f}}(S)$ failure probabilities under the punching and sliding failure modes respectively 
$P_{\mathrm{f}}(P \cap S)$ failure probability under the punching and sliding failure modes

$P_{\text {fsys }} \quad$ system failure probability

$\mathbf{R}$ correlation matrix

$R_{\mathrm{u}} \quad$ vertical component of the ultimate foundation load

$S_{\mathrm{u}} \quad$ ultimate sliding resistance of the footing

$u$ distance that separates any two points of the two segments $L_{i}$ and $L_{j}$

$u_{i}^{*} \quad$ standard normal uncorrelated variable at the design point

$V, H$ footing vertical and horizontal load components

$V_{i} \quad$ velocity of block $i$

$V_{i, i+1}$ interblock velocity between blocks $i$ and $i+1$

$\boldsymbol{x}$ random vector

$Z(x, y)$ two dimensional random field

$\bar{Z}(x, y)$ mean of the random field

$\Phi(\cdot)$ cumulative distribution function (CDF) of a standard normal variable

$\alpha_{i}, \beta_{I}$ geometrical parameters of the failure mechanism

$\alpha_{P}, \alpha_{S}$ sensitivity factors of the punching and sliding modes

$\beta_{\mathrm{HL}} \quad$ Hasofer-Lind reliability index

$\beta_{P}, \beta_{S}$ reliability indexes of the punching and sliding failure modes

$\beta_{\text {sys }}$ system failure probability

$\delta$ angle of friction at the soil-footing interface

$\delta x, \delta y$ horizontal and vertical lag distances

$\gamma$ soil unit weight

$\varphi$ angle of internal friction of the soil

$\varphi_{o i}, c_{o i}$ average values along segment $d_{i}$ of the angle of internal friction and the cohesion respectively

$\varphi_{\mathrm{r} i}, c_{\mathrm{ri}}$ average values along segment $l_{i}$ of the angle of internal friction and the cohesion respectively

$u$ mean value vector

$\mu_{c}, \mu_{\varphi}$ average values of the cohesion and angle of internal friction

$\mu_{\mathrm{H}}, \mu_{\mathrm{V}}$ mean values of the horizontal and vertical load components

$\rho$ correlation coefficient

$\rho\left(L_{i}, L_{j}\right) \quad$ average correlation between lines $L_{i}$ and $L_{j}$

$\rho_{\text {PS }}$ correlation between the sliding and punching failure modes

$\rho(u)$ autocorrelation function

$\sigma$ standard deviation vector

\section{REFERENCES}

Bhattacharya, G., Jana, D., Ojha, S. \& Chakraborty, S. (2003). Direct search for minimum reliability index of earth slopes. Comput. \& Geotech. 30, No. 6, 455-462.

Cherubini, C. (2000). Reliability evaluation of shallow foundation bearing capacity on C', $\varphi^{\prime}$ soils. Can. Geotech. J. 37, No. 1, 264-269.

Christian, J., Ladd, C. \& Baecher, G. (1994). Reliability applied to slope stability analysis. J. Geotech. Engng, ASCE 120, No. 12, $2180-2207$.

Degroot, D. \& Baecher, G. (1993). Estimating autocovariance of insitu soil properties. J. Geotech. Engng, ASCE 119, No. 1, 147166.

Fenton, G. (1999). Estimation for stochastic soil models. J. Geotech. Geoenviron. Engng, ASCE 125, No. 6, 470-485.

Fenton, G. A. \& Griffiths, D. V. (2003). Bearing capacity prediction of spatially random C- $\varphi$ soils. Can. Geotech. J. 40, No. 1, $54-65$.

Griffiths, D. V., Fenton, G. A. \& Manoharan, N. (2002). Bearing capacity of rough rigid strip footing on cohesive soil: Probabil- istic study. J. Geotech. Geoenviron. Engng., ASCE 128, No. 9, $743-755$.

Haldar, A. \& Mahadevan, S. (2000). Probability, reliability and statistical methods in engineering design. New York: Wiley.

Harr, M. E. (1987). Reliability-based design in civil engineering. New York: McGraw-Hill.

Hasofer, A. M. \& Lind, N. C. (1974). Exact and invariant secondmoment code format. J. Engng Mech., ASCE 100, No. 1, 11121.

Knabe, W., Przewlocki, J. \& Rozynski, G. (1998). Spatial averages for linear elements for two-parameters random field. Prob. Engng Mech. 13, No. 3, 147-167.

Lacasse, S. \& Nadim, F. (1996). Uncertainties in characterizing soil properties. Uncertainty in the geologic environment, pp. 49-75. Madison: ASCE.

Lemaire, M. (2005). Fiabilité des structures. Paris: Hermes, Lavoisier. In French.

Low, B. K. \& Phoon, K. K. (2002). Practical first-order reliability computations using spreadsheet. Probabilistics in geotechnics: technical and economic risk estimation, pp. 39-46. Austria: Graz.

Low, B. K., Gilbert, R. B. \& Wright, S. G. (1998). Slope reliability analysis using generalized method of slices. J. Geotech. \& Geoenviron. Engng, ASCE 124, No. 4, 350-362.

Low, B. K. \& Tang, W. H. (1997). Efficient reliability evaluation using spreadsheet. J. Engng. Mech., ASCE 123, No. 7, 749-752.

Lumb, P. (1970). Safety factors and the probability distribution of soil strength. Can. Geotech. J., 7, No. 3, 225-242.

Melchers, R. (1999). Structural reliability analysis and prediction. Chichester: Wiley.

Mostyn, G. R. \& Li, K. S. (1993). Probabilistic slope analysis state-of-play. Probabilistic methods in geotechnical engineering, pp. 89-109. Balkema: Rotterdam.

Orr, T. L. L. \& Breysse, D. (2008). Eurocode 7 and reliabilitybased design. Reliability-based design in geotechnical engineering: computations and applications, chapter 8 (ed. K. K. Phoon). London/New York: Taylor \& Francis.

Phoon, K.-K. \& Kulhawy, F. H. (1999). Evaluation of geotechnical property variability. Can. Geotech. J. 36, No. 4, 625-639.

Popescu, R. (1995). Stochastic variability of soil properties: dato analysis, digital simulation, effects on system behaviour. $\mathrm{PhD}$ thesis, Princeton University, Princeton, NJ.

Popescu, R., Deodatis, G. \& Nobahar, A. (2005). Effect of random heterogeneity of soil properties on bearing capacity. Probabilistic Engng Mech. 20, No. 4, 324-341.

Przewlocki, J. (2000). Two-dimensional random field of mechanical soil properties. J. Geotech. Geoenviron. Engng, ASCE 126, No. 4, 373-377.

Sivakumar Babu, G. L. \& Mukesh, M. D. (2004). Effect of soil variability on reliability of soil slopes. Géotechnique 54, No. 5, $335-337$.

Soubra, A.-H. (1999). Upper-bound solutions for bearing capacity of foundations. J. Geotech. Geoenviron. Engng, ASCE 125, No. $1,59-68$.

Soubra, A.-H., Thorel, L. \& Garnier, J. (2003). Effet de l'inclinaison de la charge sur la portance des fondations superficielles: étude théorique et expérimentale. FONDSUP 2003: symposium international sur les fondations superficielles, Paris 1, 463-470. In French.

Vanmarcke, E. (1983). Random fields: analysis and synthesis. Cambridge, MA: MIT Press.

Wolff, T. H. (1985). Analysis and design of embankment dam slopes: A probabilistic approach. $\mathrm{PhD}$ thesis, Purdue University, Lafayette.

Yuceman, M. S., Tang, W. H. \& Ang, A. H. S. (1973). A probabilistic study of safety and design of earth slopes. Civil Engineering Studies, Structural Research, series 402, University of Illinois, Urbana. 